\title{
1.17
}

\section{O direito ao saneamento como fator social de saúde no Brasil}

The right to sanitation as a social factor of health in Brazil

\section{Mariana Almeida Picanço de Miranda}

Advogada, Mestre em direito. Escola de Magistratura do Estado do Rio de Janeiro (EMERJ). Rio de Janeiro, Brasil.

\section{Luisa Almeida Picanço de Miranda}

Jornalista, Especialista. Universidade de Brasília (UnB). Rio de Janeiro, Brasil.

\section{Marilucia Rocha de Almeida Picanço}

Professora universitária e médica, Pós-doutora em medicina. Universidade de Brasília (UnB). Brasília, Brasil.

Resumo: Este artigo tem como proposta apresentar a direta relação entre saneamento e saúde pública no Brasil. Teve como base revisão bibliográfica e análise de dados fornecidos pelo SNIS. Observou-se que existem no Brasil dois desafios do setor de saneamento que interferem diretamente na questão da saúde pública: regularidade do abastecimento de água e tratamento de esgoto. Apesar dos serviços de abastecimento de água no Brasil serem considerados praticamente universalizados, não há nenhuma regularidade no seu fornecimento, pois conforme dados apresentados pelo SNIS, a média da intermitência nas economias ativas é cerca de $40 \%$. Ou seja, quase a metade dos domicílios no país não tem segurança no abastecimento de água. No entanto, a escassez no tratamento dos esgotos ainda é o maior desafio para o setor de saneamento brasileiro, já que os principais rios brasileiros ainda recebem esgotos in natura. O SNIS aponta que em 2011 a média nacional de tratamento de esgoto foi de 37,5\%: ou seja, a maior parte da água que entra em contato com as pessoas é poluída. Diversas ações em prol da melhoria do setor estão sendo tomadas, inclusive no campo legal. Exemplo disso é a lei 12.305/2010, que estabelece a Política Nacional de Resíduos Sólidos, cujos objetivos principais são a proteção da saúde pública e da qualidade ambiental, e o tratamento de resíduos sólidos. Este artigo pretende, portanto, além de demonstrar a relação entre saúde e saneamento, mostrar como a legislação pode interferir na melhoria da qualidade de vida dos cidadãos brasileiros. 
Palavras-chave: Saneamento; Saúde Pública; Legislação; Sociedade.

Key-words: Sanitation; Public Health; Law; Society.

\section{Introdução}

A correlação entre o direito e a saúde é um tema atual, que tem recebido mais atenção por parte dos pesquisadores, não se limitando mais somente às escolas de saúde pública, mas começando a fazer parte da formação dos profissionais do direito também.

Esta é uma tendência global, não se restringindo apenas ao Brasil, e tem como base o convencimento de que a saúde é também uma questão de direito e, portanto, merece uma maior preocupação por parte dos Estados Democráticos de Direito, que devem fazer de tudo para garanti-la, utilizando-se da legislação como mais um meio de garantia dessa direito, juntamente com as ações de políticas públicas.

Conforme preleciona Sueli Dallari, "no Brasil esse campo do conhecimento, que cuida da ciência pura do direito e da saúde pública e de suas implicações práticas, nas políticas públicas e nos tribunais, recebeu o nome de direito sanitário" (Dallari, 2011, p. 01).

Dentro deste vasto campo do direito sanitário, emerge uma questão aparentemente óbvia, mas que ainda precisa ser muito cuidada, que é a interrelação entre a saúde pública e o saneamento. O artigo $3^{\circ}$ da lei $n^{\circ}$ 11.445/07 define o saneamento como o conjunto de serviços, infraestruturas e instalações de abastecimento de água, esgotamento sanitário, limpeza urbana e manejo de resíduos sólidos e drenagem de águas pluviais urbanas.

A ideia de um meio ambiente saudável como fator de saúde existia desde antes de Cristo, quando Hipócrates (Dallari, 2011, p. 01) dizia que "uma pessoa só teria saúde quando vivesse em perfeito equilíbrio com o meio ambiente". Entretanto, as revoluções sofridas pelo mundo a partir do século XVIII acabaram por desassociar essa ligação, delimitando a área da saúde pública como atendimento médico e ambulatorial, e a área do meio ambiente como preservação da fauna e da flora (Dallari, 2011).

No entanto, é óbvia a constatação de que para se ter saúde não se pode ter um esgoto a céu aberto, nem podemos despejar esgotos in natura diretamente nos rios, sob o risco de se ter mais e mais pessoas doentes, apesar de terem 
medicamentos adequados, pois a medicação não é suficiente para se manter saúde. É preciso, sim, um meio ambiente saudável e, portanto, um saneamento básico adequado.

Assim é que o presente artigo tem como proposta apresentar a direta relação entre saneamento e saúde pública no Brasil, traçando, para isso, um levantamento histórico, bem como a necessidade de uma maior legislação sobre o tema. Para tanto, o estudo foi realizado com base em revisão bibliográfica, bem como análise de dados fornecidos pelo Sistema Nacional de Informações sobre Saneamento (SNIS).

No levantamento dessa pesquisa, foi possível perceber que existem no Brasil dois grandes desafios relacionados ao setor de saneamento que interferem diretamente na questão da saúde pública: regularidade do abastecimento de água e tratamento de esgoto.

Grande parte dos estados brasileiros tem os serviços de abastecimento de água praticamente considerados universalizados em seus centros urbanos, conforme comprovam dados do SNIS: em 2011, dezenove estados brasileiros tiveram cerca de 90\% do seu estado abastecido. Entretanto, não há nenhuma regularidade no seu fornecimento, pois, ainda de acordo com os dados apresentados pelo SNIS, a média da intermitência nas economias ativas (domicílios regulares) foi cerca de $40 \%$. Ou seja, quase a metade dos domicílios no país não tem segurança no abastecimento de água (Brasil, SNSA, 2013).

No entanto, a escassez no tratamento dos esgotos ainda é o maior desafio para o setor de saneamento brasileiro, o que atinge diretamente a saúde pública. Isso ocorre, porque os principais rios brasileiros ainda recebem a maior parte dos esgotos in natura. De acordo com o SNIS, em 2011, a média nacional de tratamento de esgoto foi de $37,5 \%$. A região Centro-Oeste foi a que apresentou a maior média, de $44 \%$. Isso significa que o país ainda polui as águas que estarão em contato com as pessoas (Brasil, SNSA, 2013).

Diversas ações em prol da melhoria do setor saneamento no país estão sendo tomadas, inclusive no campo legal. Exemplo disso é a Lei 12.305/2010, que estabelece a Política Nacional de Resíduos Sólidos, cujos objetivos principais são a proteção da saúde pública e da qualidade ambiental, bem como a redução, reutilização, reciclagem, tratamento de resíduos sólidos, dentre outros. De fato, a política de saneamento básico no Brasil é uma questão constitucional, já que a Carta 
Magna atribui como responsabilidade do Sistema Único de Saúde (SUS) o dever de "participar da formulação da política de saneamento básico", nos termos do seu artigo 200, IV.

Dessa forma, tem-se a relevância no estudo do tema do direito ao saneamento básico como um direito fundamental à saúde. É, portanto, de extrema urgência que a justiça (e o mundo jurídico) comece a se envolver diretamente como ator social nessa questão, já que tais direitos estão ligados à proteção da vida, bem maior, garantindo e assegurado pela Constituição da República, sob pena de violação constitucional.

Este artigo pretende, portanto, além de demonstrar a relação entre saúde pública e saneamento, também trazer à sociedade a reflexão de como a legislação pode interferir positivamente nesta questão, apresentando, inclusive, marcos históricos relevantes para a melhoria da qualidade de vida dos cidadãos brasileiros.

\section{Breve resumo histórico sobre o saneamento e a saúde no mundo}

A relação entre saúde e saneamento no mundo envolve a história do desenvolvimento das civilizações, já que o processo de evolução do ser humano e sua sobrevivência no mundo estão diretamente ligados a essas questões.

Já nas antigas sociedades verifica-se existir uma visão, ainda que intuitiva, de uma relação entre saúde e saneamento, mas ligada à questão da religiosidade. Daí surgiu a necessidade dos mais diversos povos de se utilizarem de água pura e de afastarem os dejetos de seu convívio. Hipócrates, na Grécia, já estudava a relação entre a propagação de doenças e os aspectos ambientais, quando de sua obra "Dos ares, das águas e dos lugares" (Ribeiro, 2004).

Entretanto, com a chegada do período medieval, houve uma mudança nas prioridades sociais, passando a segurança a ter um maior espaço, em virtude das constantes ameaças de guerra e barbáries. Assim, a relação saúde-saneamento perdeu importância, razão pela qual o número de mortes em epidemias, como a Peste Negra, aumentou consideravelmente. E é somente com o surgimento da burguesia, e posteriormente, com a Revolução Industrial, que houve um novo desenvolvimento para o saneamento e para a saúde. Entretanto, não houve necessariamente uma relação entre os temas, passando a saúde a tratar especificamente das questões médico-ambulatoriais, e o saneamento apenas com a 
preservação, não se falando mais em saúde-saneamento, e sim em saúde-doença (Rezende, 2008, p. 356).

De fato, com as condições de vida precárias das cidades, a partir da revolução Industrial surgem as primeiras reformas sanitárias, para evitar a constante ameaça de epidemias. A necessidade de se garantir a saúde do trabalhador, para dar conta do sistema capitalista, fez surgir um investimento maior em saneamento e saúde por parte dos novos países emergentes (Inglaterra, França, Estados Unidos e Alemanha), estabelecendo assim, uma universalização dos serviços. É um período marcado, então, por intensas modificações nos espaços urbanos, o que significou um grande avanço na área de saneamento (Rezende, 2008, p. 357).

Ou seja, o processo econômico acabou impulsionando o desenvolvimento das ações sanitárias, já que há uma demanda por mercados e serviços pelos serviços de saneamento. Há uma relação direta entre os mercados externos desenvolvidos pelos países capitalistas dominantes e seu mercado interno. Entretanto, não se pode falar o mesmo para os países subdesenvolvidos, já que sua realidade é o contrário dos países desenvolvidos. Nesse contexto está o Brasil (Rezende, 2008, p. 357).

\section{O Saneamento e a saúde no Brasil}

O Brasil colonial não teve qualquer preocupação com o cenário de saneamento, muito menos em relacioná-lo com a questão da saúde, já que os habitantes que vinham para a colônia tinham a intenção de uma vida provisória, sem criar raízes. A ideia inicial era apenas extrair da terra tudo o que fosse possível, e partir o mais breve possível. Os poucos cuidados para a manutenção da salubridade do meio eram consequência de iniciativas meramente individuais, ou de um pequeno grupo, como o caso dos povos indígenas (Novais, 1997).

Sem dúvidas, o modus operandi dos povos indígenas brasileiros contribuiu muito para a consolidação de uma identidade sanitária brasileira, já que estes são conhecidos pelo uso de água pura para o consumo e higiene pessoal, além de destinarem um lugar específico para a realização de suas necessidades fisiológicas e disposição do lixo produzido. No entanto, apesar dos cuidados indígenas, a saúde e o saneamento não foram, de fato, preocupação no período colonial. Entretanto, por conta da abundância de recursos naturais e da imensidão territorial, esse despreparo não causou problemas mais graves para o país (Rezende, 2008, p. 358). 
É no período do ciclo do ouro no Brasil que começa-se a adquirir contornos de povoamentos, e nasce daí um mercado interno, promovendo mudanças estruturais na sociedade brasileira, inclusive em relação ao saneamento, de maneira ainda tímida. Porém, é a partir do século XIX, que a Inglaterra volta-se para esse novo mercado consumidor emergente, o que obriga o Brasil (já ex-colônia) a abolir o sistema de escravatura, a proclamar a República, e a povoar o país com a imigração estrangeira. Tudo em consonância com o capitalismo mundial. E é a participação dos ingleses nesse processo que faz surgir as primeiras companhias prestadoras de serviços de saneamento no Brasil, e começam a ser delineados os primeiros contornos de uma relação entre saúde e saneamento no país (Rezende, 2008, p. 358-359).

No fim do século $X I X$, início do século $X X$, percebe-se que há, de fato, um maior investimento e melhoria na situação do saneamento, mas tão somente em parte do Brasil. Isso porque, de fato, passam a existir dois países: um dinâmico e rico, e outro pobre e excluído de qualquer benefício de políticas públicas, dentre elas o saneamento. A principal preocupação estatal era na prevenção de doenças nas cidades urbanas e no controle das epidemias generalizadas pelo país, como a varíola e a febre amarela, que atingiam os "sertões" brasileiros. Daí surgiu a alcunha do Brasil como uma "imenso hospital", razão pela qual começa a surgir um novo interesse na política do saneamento (Rezende, 2008, p. 359-360).

Assim, a política de saneamento no Brasil começa a ser vista como um instrumento de desenvolvimento econômico. O Plano Nacional de Saneamento PLANASA, por exemplo, permitiu um grande desenvolvimento de políticas voltadas ao saneamento. Entretanto, apenas as populações urbanas continuaram privilegiadas de um sistema de saneamento desenvolvido, enquanto que o interior do país continuou marginalizado de políticas públicas, ainda que tenha havido um maior controle nas epidemias nessas regiões (Salles, 2009).

Além disso, a dicotomia que separa saneamento e saúde ampliou-se ainda mais, traduzindo, portanto, o atual cenário brasileiro: um sistema de saneamento cada vez mais desenvolvido, mas pouco distribuído, o que contribui para o aumento de doenças como a diarréia e a cólera, por exemplo (Brasil, 2004).

Assim é que, no levantamento do presente estudo, foi possível observar que existem no Brasil dois grandes desafios relacionados ao setor de saneamento que interferem diretamente na questão da saúde pública: a regularidade do abastecimento 
de água e o tratamento de esgoto. E, de fato, a legislação pode ser uma grande aliada para a universalização dessa relação entre saúde e saneamento.

\section{A regularidade do abastecimento de água e o tratamento de esgoto no Brasil}

Grande parte dos estados brasileiros tem os serviços de abastecimento de água praticamente considerados universalizados em seus centros urbanos, conforme comprovam dados do SNIS: em 2011, dezenove estados brasileiros tiveram cerca de 90\% do seu estado abastecido. Entretanto, não há nenhuma regularidade no seu fornecimento, pois, ainda de acordo com os dados apresentados pelo SNIS, a média da intermitência nas economias ativas (domicílios regulares) foi cerca de $40 \%$. Ou seja, quase a metade dos domicílios no país não tem segurança no abastecimento de água (Brasil, SNSA, 2013).

A Agência Nacional de Águas (2010, p. 14) define o abastecimento intermitente como "aquele provocado pela produção de água em quantidades inferiores às demandas, em função da precariedade e deterioração dos sistemas de captação, adução e tratamento de água e de elevados índices de perdas".

Ou seja, não há regularidade na distribuição de água limpa e tratada, o que ocasiona locais com completa falta de higiene, banhos em águas contaminadas, e o uso de água não tratada, ocasionando as mais diversas doenças. A intermitência de água é, portanto, sem dúvidas, um fator social de saúde no Brasil.

No entanto, a escassez no tratamento dos esgotos ainda é o maior desafio para o setor de saneamento brasileiro, o que atinge diretamente a saúde pública. Isso ocorre, porque os principais rios brasileiros ainda recebem a maior parte dos esgotos in natura. De acordo com o SNIS, em 2011, a média nacional de tratamento de esgoto foi de $37,5 \%$. A região Centro-Oeste foi a que apresentou a maior média, de $44 \%$. Isso significa que o país ainda polui as águas que estarão em contato com as pessoas (Brasil, SNSA, 2013).

O Instituto Trata Brasil aponta que, em 2010, só 23 cidades brasileiras (das mais de 5.500 cidades no país) coletavam mais que $90 \%$ do esgoto que geravam, o que significou uma média nacional de tratamento de esgoto no referido ano de apenas 38\% das cidades. Tais dados apontam diretamente para o maior problema da falta de tratamento dos esgotos: os detritos são jogados diretamente (in natura) para os rios, o que aumenta o número de doenças como a diarréia e abarrota o sistema de 
saúde. Prova da necessidade imperiosa de que o direito ao saneamento básico é um fator social de extrema importância para a garantia da saúde (Instituto Trata Brasil, 2013).

Reflexo dessa escassez de saneamento é o índice de quase $40 \%$ de internações hospitalares por diarréias, doença claramente ligada à falta de saneamento básico. Grande número dessas internações (tendo como conseqüência mais grave as mortes) são de crianças, que vivem em péssimas condições de higiene. Dados da Organização Mundial de Saúde (OMS) apontam que 88\% das mortes por diarreia no mundo são fruto de saneamento inadequado; $84 \%$ desses óbitos são de crianças, sendo a diarreia a segunda causa mais prevalente em mortes de crianças abaixo de 5 anos no mundo. Estima-se que cerca de 1 milhão e 500 mil crianças morrem todo ano por conta de diarreias no mundo todo (Instituto Trata Brasil, 2013).

Ora, sem uma política adequada de saneamento não tem como se esperar uma população saudável, claro. O direito ao saneamento básico traz o acesso à água tratada, coleta e tratamento devidos de esgoto, destinação final adequada para o lixo. E tudo isso traz saúde, pois todos estes serviços estão diretamente relacionados à proteção da saúde, ou seja, a proteção da vida, bem maior tutelado pelo direito.

A falta de um adequado sistema de tratamento de esgotos também afeta diretamente o desenvolvimento econômico da saúde pública no Brasil. Dados apresentados pelo mesmo Instituto Trata Brasil (2013) apontam que só em 2011, os gastos do Sistema Único de Saúde (SUS) brasileiro com internações por diarréia foram de $R \$ 140$ milhões. Ora, houvesse uma política adequada de saneamento no país, não haveria um gasto exagerado (e completamente desnecessário) com controle de diarréia pelo SUS.

Urge a efetivação da regularidade do abastecimento de água no país, bem como um correto tratamento de esgoto, ambos em sintonia e universalidade, como forma de prevenção e controle de doenças, garantindo uma melhor qualidade de vida dos cidadãos brasileiros, com seu direito à saúde assegurado. Sem dúvidas, a atuação da justiça brasileira é amplamente necessária, para que as legislações na área sejam devidamente cumpridas, em prol de uma saúde pública de qualidade para a sociedade brasileira. 


\section{A Legislação como forma de garantia do direito ao saneamento adequado e o desenvolvimento da saúde no Brasil}

Apesar das dificuldades enfrentadas pelo setor de saneamento e abastecimento de água, o Brasil conta, desde 2007, com uma série de garantias e direitos dos cidadãos assegurados pela Lei do Saneamento básico (Lei no 11.445/07) e a Lei 12.305/10, que instituiu a Política Nacional de Resíduos Sólidos (PNRS) considerada um marco regulatório fundamental para instituir uma política de resíduos sólidos.

Conforme disposto no site do Governo Federal, "a legislação federal prevê a universalização dos serviços de abastecimento de água e tratamento da rede de esgoto para garantir a saúde dos brasileiros, e estabelece as regras básicas para o setor ao definir as competências do governo federal, estados e prefeituras para serviços de saneamento e água, além de regulamentar a participação de empresas privadas no saneamento básico" (Brasil, 2012, p. 1).

Estas leis vêm apenas cumprir o já estabelecido na Constituição da República, que em seu artigo 200, IV, torna o saneamento como um direito à saúde, e são, sem dúvidas, instrumentos para o avanço das políticas públicas de saneamento, e devem ser entendidos (e utilizados) como fator de garantia da saúde no Brasil.

Entretanto, apesar da garantia constitucional e das novas legislações que tratam especificamente sobre o tema, o saneamento ainda é encarado "como uma medida de infra-estrutura das cidades, como um investimento necessário à reprodução do capital, como um serviço que deveria ser submetido à lógica empresarial, tendo a auto-sustentação um pressuposto fundamental" e não necessariamente como uma medida de saúde pública e, conseqüentemente integrante da política social (Borja; Moraes, 2005, p. 9).

De fato, o país está avançando, ainda que lentamente, no entendimento do saneamento como um fator social do direito à saúde. Prova disso é o compromisso firmado pelo Brasil com os Objetivos do Milênio das Nações Unidas e a instituição de 2009-2010 como o Biênio Brasileiro do Saneamento (Decreto № 6.942/09), com o propósito de mobilizar para o alcance da meta de, até o ano de 2015, reduzir pela metade a proporção de pessoas que não contam com saneamento básico, surgindo daí o "Pacto pelo Saneamento Básico" (Brasil, 2013). 
Some-se a isso a aliança entre o Ministério do Meio Ambiente e o Ministério das Cidades, quando firmaram o "Compromisso pelo Meio Ambiente e Saneamento Básico" que consiste em um conjunto de ações em curso ou a serem estruturadas para atingir metas intermediárias preconizadas pela Lei de Saneamento Básico até o ano de 2020 (Brasil, 2013).

As ferramentas para a efetiva extensão da cobertura dos serviços de coleta e tratamento de esgoto no Brasil de fato existem, basta um pouco mais de empenho por parte do Poder Público para a devida implementação das adequadas políticas públicas. Infelizmente ainda faltam medidas mais combativas não só em relação ao saneamento, mas também para a intermitência de água no país, o que gera condições de higiene inadequadas o, consequentemente, também gera problemas de saúde, como a diarréia. Sem água potável não temos limpeza, fato.

É preciso também uma maior participação da sociedade na formulação da política de saneamento, que deve cobrar a efetivação da lei diretamente de seus Municípios. Além disso, é preciso uma maior atuação por parte do Ministério Público, tanto na proteção da saúde, quanto na proteção do meio ambiente, já que é sua função institucional zelar pelo efetivo respeito dos serviços de saúde aos direitos constitucionais, promovendo as medidas necessárias para sua garantia e também proteger o meio ambiente, nos termos do art. 129, II e III, da Carta Magna (Dallari, 2011).

\section{Conclusão: perspectivas e realidade}

A Organização Mundial de Saúde (OMS) sustenta que o saneamento básico precário é uma ameaça à saúde humana. A história mostra que há uma evolução no cuidado com o saneamento, mas que ainda falta a compreensão de que o adequado saneamento está intimamente ligado à proteção à saúde.

Fato é que, no Brasil, apenas as grandes cidades têm uma melhor qualidade no serviço prestado de saneamento básico e abastecimento de água. Ainda há muito o que se fazer pelo interior do país, abandonado pelos governantes, sem um correto abastecimento de água, e sem uma devida coleta e tratamento de esgotos.

Os dados são claros: apenas 50,65\% das populações urbanas em 2013 terão acesso a rede de esgoto. Isso significa que ainda falta muito para a garantia de um 
dos direitos mais básicos do ser humano: o direito à saúde, que começa com o direito à água potável e tratada e ao saneamento básico (Instituto Trata Brasil, 2013).

É imperioso que haja uma profunda mudança na implementação das políticas públicas voltadas ao saneamento básico: tem de haver uma relação profunda com a garantia da saúde. Um tema está completamente ligado ao outro. Apesar de existirem leis como ferramentas para estas implementações, é preciso mais. A sociedade deve se entender também como ator social dessa implementação de mudanças, pois tratam-se de políticas públicas voltadas ao bem estar coletivo.

Da mesma forma devem os operadores do direito, especialmente o Ministério Público, participar dessas propostas, evitando, inclusive, que o Poder Judiciário seja constrangido a exigir o cumprimento da lei, e garantindo a saúde como direito fundamental que é. As mudanças são necessárias e a participação de todos imprescindíveis.

\section{Referências}

AGÊNCIA NACIONAL DE ÁGUAS. Atlas Brasil: Abastecimento Urbano de Água. Panorama Nacional. Vol. 1. Brasília: Agência Nacional de Águas, 2010.

ANDREAZZI, M A R; BARCELLOS, C; HACON, S. Velhos indicadores para novos problemas: a relação entre saneamento e saúde. Revista Panamericana de Salud Publica, Washington, 22(3):211-217, 2007.

BORJA, Patrícia Campos; MORAES, Luiz Roberto Santos. Saneamento como um direito social. Belo Horizonte: ASSEMAE, 2005 [on line]. Disponível em: http://www.saneamentobasico.com.br/portal/wp-

content/uploads/2013/02/SANEAMENTO-COMO-UM-DIREITO-SOCIAL.pdf . [data da consulta: 13 set. 2013].

BRASIL. Lei do Saneamento Básico garante direitos aos usuários de serviços de água e esgoto. Brasília: Portal Brasil, 2012 [on line]. Disponível em: http://www.brasil.gov.br/cidadania-e-justica/2012/04/lei-do-saneamento-basico-

garante-direitos-aos-usuarios-de-servicos-de-agua-e-esgoto. Consulta realizada em 14 set. 2013.

BRASIL. Secretaria Nacional de Saneamento Ambiental (SNSA). Sistema Nacional de Informações sobre Saneamento: Diagnóstico dos Serviços de Água e Esgotos - 2011. Brasília: Min. das Cidades, 2013.

BRASIL. Ministério da Saúde. Organização Pan-Americana da Saúde. Avaliação de impacto na saúde das ações de saneamento: marco conceitual e estratégia metodológica. Brasília: Ministério da Saúde, Organização Pan-Americana da Saúde, 2004.

BRASIL, Ministério do Meio Ambiente. Plano Nacional de Saneamento. Brasília: Ministério das Cidades e do Meio Ambiente, 2013 [on line] Disponível em: 
http://www.mma.gov.br/cidades-sustentaveis/residuos-solidos/instrumentos-da-politicade-residuos/plano-nacional-de-saneamento-basico . Data da consulta: 13 set. 2013. (a)

DALLARI, Sueli Gandolfi. Direito ao saneamento básico: interesse da saúde pública, do meio ambiente e da Justiça. São Paulo: Instituto Trata Brasil, 2011. Disponível em: http://www.tratabrasil.org.br/direito-ao-saneamento-basico-interesse-da-saude-publicado-meio-ambiente-e-da-justica-envolverde [data da consulta: 10 set. 2013]

FIGUEIRA, Carlos Augusto Ferreira. O papel da saúde pública no processo de concretização do Estado Nacional Brasileiro. Rio de Janeiro: Unirio, 2005 [data da $\begin{array}{lllll}\text { consulta } & 9 & \text { set. } & 2013] & \text { Disponível }\end{array}$ http://www.memoriasocial.pro.br/linhas/arouca/desdobramentos/papeldasaude.htm .

GOUVEIA, Nelson. Saúde e meio ambiente nas cidades: os desafios da saúde ambiental. São Paulo: Saúde e sociedade, 1998 [data da consulta: 9 de set. 2013] Disponível em: http://www.scielo.br/pdf/sausoc/v8n1/05.pdf .

INSTITUTO TRATA BRASIL. Esgotamento sanitário inadequado e impactos na saúde da população: atualização do diagnóstico da situação nas 100 maiores cidades brasileiras. São Paulo: Instituto Trata Brasil, 2013 [on line] Disponível em: http://www.tratabrasil.org.br/datafiles/uploads/drsai/Book-Trata-B.pdf . [data da consulta: 10 set. 2013]

NOVAIS, Fernando Antonio. Condições da privacidade na colônia. Em: NOVAIS, Fernando Antonio; SOUZA, Laura de Mello e. (Orgs.) História da vida privada no Brasil: cotidiano e vida privada na América portuguesa. Vol. 1, p. 13-40. São Paulo: Companhia das Letras, 1997.

REZENDE, Sonaly Cristina. O saneamento no Brasil: políticas e interfaces. $2^{\underline{a}}$ ed. Belo Horizonte: Editora UFMG, 2008, pag. 356.

RIBEIRO, Helena. Saúde Pública e meio ambiente: evolução do conhecimento e da prática, alguns aspectos éticos. São Paulo: Saúde Soc., 13(1), 2004. [on line] Disponível em: $\quad$ http://www.scielo.br/scielo.php?script=sci arttext\&pid=S010412902004000100008\&lng=en\&nrm=iso [data da consulta: 10 set. 2013]

SALLES, Maria José. Política nacional de saneamento: percorrendo caminhos em busca da universalização. Tese (Doutorado). Rio de Janeiro, Escola Nacional de Saúde Pública Sergio Arouca, 2009.

SIQUEIRA, Dirceu Pereira. O direito fundamental à saúde: dos Direitos Humanos à Constituição de 1988. Rio Grande do Sul: Âmbito Jurídico, 1:20-26, 2008. [on line] Disponível em: http://www.ambitojuridico.com.br/site/index.php?n link=revista artigos leitura\&artigo id=2970 . [data da consulta 09 set. 2013] 